\title{
Improvement in the manufacturing process of the motorcycle gear part
}

\author{
Bruno Marques dos Santos ${ }^{1}$, Fernando Neves de Almeida ${ }^{1}$, Railey Martins Braga ${ }^{1}$, Luiz Felipe de Araújo \\ Costa $^{1}$
}

1,2,3,4 Graduando do curso de Gestão da Produção Industrial da Faculdade Metropolitana de Manaus (FAMETRO). Avenida Constantino Nery 3204. CEP: 69050-000. Manaus - Amazonas - Brasil. Telefone: +55 (92) 36423770 Fax: +55 (92) 36423770.

Email: brunom859@gmail.com, nevesfernando71@gmail.com, raileybraga@gmail.com, luizfelipe_am@hotmail.com

Received: January $13^{\text {th }}, 2017$

Accepted: February $14^{\text {th }}, 2017$

Published: March 30 1 th 2017

Copyright $\odot 2016$ by authors and Institute of Technology Galileo of Amazon (ITEGAM). This work is licensed under the Creative Commons Attribution International License (CC BY 4.0).

http://creativecommons.org/licenses/by/4.0/ (c) (i) (2)(2) Open Aecen:

\begin{abstract}
The article aims to improve the manufacturing process of the gear for the elimination of burr and rework, which caused a handling and disposal of damaged parts, done in a way that did not guarantee the quality of the product, with loss of time and productivity. The analysis in the compacting process to form the gear has in its tooling structure openings between the movable punches where the excess burr occurs, with its non-standard specification, in this way the excess material must be removed This gap between the punches. With the adjustment in the tooling where it was modified for a single piece, if there is no gap between punches, thus, after adjustment in the punch, the burr has been eliminated, as well as the rework and its handling, guaranteeing the quality of the part.
\end{abstract}

Keywords: Improvement; Discard; Adjustment; Eliminating.

\section{Melhoria no processo de manufatura da peça de engrenagem da motocicleta}

\section{RESUMO}

$\mathrm{O}$ artigo em estudo tem como proposta a melhoria no processo de fabricação da engrenagem para a eliminação da rebarba e retrabalho, que ocasionava um manuseio e descarte de peças danificadas, feito de forma que não garantia a qualidade do produto, com perda de tempo e produtividade. A análise no processo de compactação para formar a engrenagem, tem em sua estrutura ferramental aberturas entre os punções móveis onde se dá o excesso de rebarba, com a sua especificação fora do padrão, desta forma terá que se fazer a retirada do excesso de material proveniente desta folga entre os punções. Com o ajuste no ferramental onde foi modificado para uma peça inteiriça, se não terá folga entre punções, assim sendo, após o ajuste na punção, a rebarba foi eliminada, assim também o retrabalho e seu manuseio, garantindo a qualidade da peça.

Palavras-chave: Melhoria; Descarte; Ajuste; Eliminando.

\section{INTRODUÇÃO}

As engrenagens possuem uma história longa. Um aparato denominado "carroça chinesa apontada para o Sul" supostamente usada para navegar pelo deserto de Gobi nos tempos pré-bíblicos, continha engrenagens rudimentares. Após um grande desenvolvimento e o advento da revolução industrial, as engrenagens passaram a ser fabricadas com materiais metálicos muito mais resistentes.

As primeiras engrenagens foram provavelmente feitas cruamente de madeira e outros materiais fáceis de serem trabalhados. Sendo meramente constituídos por pedaços de madeira inseridos em um disco ou roda. Denomina-se engrenagem o elemento dotado de dentadura externa ou interna, cuja finalidade é transmitir movimento sem deslizamento e potência, multiplicando os esforços com a finalidade de gerar trabalho.

A proposta de melhoria no processo de compactação da engrenagem é feita para que haja uma interação entre os setores e mostrar que cada um pode contribuir para que o desenvolvimento de melhoria seja eficaz e que após a implantação da proposta terá seu procedimento marcado com o desenvolvimento da eliminação do retrabalho para a retirada da rebarba.

Devido ao alto índice de retrabalho e excesso de manuseio, verificou-se que havia a necessidade de se fazer algo 
para a eliminação deste problema, assim sendo o excesso de rebarba, retrabalho e manuseio das peças que geram defeitos e são pontos que devem ser melhorados.

Eliminação da rebarba na engrenagem fabricada em ferramental composta por partes móveis e de postiços que entre peças há folgas que podem gerar excesso de rebarba, com isto a necessidade de fazer a retirada para que não ocorra um excesso de desgaste quando a peça for montada, ocasionando quebra e possível acidente ao usuário e com isto gera o não cumprimento das normas de segurança vigente. A eliminação da rebarba fará que haja melhoria em sua fabricação e colocando assim a sua qualidade dentro do especificado.

A análise com base na vivência do quadro funcional é a forma de se chegar a solução do problema, tendo em vista que cada um tem sua parte fundamental para que a realização deste trabalho seja efetiva e assim eliminar a necessidade de retirar a rebarba que gera a utilização de mais tempo e de mais um colaborador para fazer este trabalho, deixando de fazer a inspeção da qualidade da peça, após o ajuste nos ferramentais, passará a fazer o seu trabalho de inspeção da qualidade.

O presente artigo tem como objetivo geral melhorar o processo de fabricação da engrenagem. Será feito um estudo minucioso, mapeando todo processo para se chegar ao real motivo que aparece a rebarba e com isto estudar uma forma de eliminação da mesma.

Tem como objetivo específico modificar o processo de fabricação da engrenagem, propondo mudança no ferramental de compactação e formação da peça; verificar o impacto dos dados gerados pela modificação (antes e depois) para que se obtenha novos dados para ser comparado com o anterior (eficaz/não eficaz); validar a modificação proposta em conformidade ao processo de fabricação da engrenagem (compactação e formação). Utilizando as ferramentas da qualidade Brainstorming, Diagrama de Ishikawa, 5W2H, Histograma [1][2].

A análise de cada ponto, verificando-se todas as possibilidades viáveis, sendo feito de forma gradual e com pessoas envolvidas em todas as etapas, seguirá com todos os dados colhidos para que sejam avaliadas para a viabilização da melhoria e com isto a eliminação da rebarba na engrenagem.

$\mathrm{O}$ presente trabalho tem como justificativa para que a proposta de implantação seja efetuada de forma a garantir que a mudança elimine o excesso de retrabalho para retirar a rebarba, excesso de manuseio da peça, perda da produtividade que gera nãoconformidade no produto. Referente ao índice de rejeito e retrabalho dá margem para que a implantação seja eficaz para a organização.

$\mathrm{O}$ acadêmico tem a possibilidade de mostrar o seu conhecimento adquirido com a análise e com isto a solução para resolver o problema da rebarba na engrenagem, assim poderá colocar tudo que aprendeu em prática durante todo o curso e saber o que é importante para melhorar o processo produtivo, por outro lado, a empresa ganha com esta melhoria no processo de fabricação da peça, fazendo com que seja eliminado o processo de retrabalho para a retirada da rebarba, ganhando na sua produtividade e qualidade [3].

\section{FUNDAMENTAÇÃO TEÓRICA}

\section{II.1 MELHORIA CONTÍNUA}

A melhoria traz mudança e ajuste que fazem parte de um processo longo e estressante, porém com isto possa se fazer todos os procedimentos de produção fabril, e também promover os estudos que possam auxiliar nas melhorias de fabricação. As características de cada produto e mão-de-obra que devem ser utilizados de maneira a retirar o melhor neste processo de confecção de um produto com qualidade, atendendo todas as especificações e garantias.

"A melhoria contínua é um tema que, há muitos anos, vem sendo bastante explorado dentro das áreas de engenharia de produção e administração. Contudo, grande parte desses estudos foca os aspectos técnicos, atendo-se à estruturação de programas de melhoria, sem grande preocupação com aspectos culturais que regem as organizações" [4].

A consciência de melhoria contínua é a forma de conscientizar todos os envolvidos de que não é somente para ganhar tempo e melhorar a qualidade, mas sim tempo tem a melhoria para o colaborador que executará o serviço. "Tal investigação deve-se ao fato de que o êxito e a continuidade da melhoria contínua nas organizações não dependem apenas da adoção de ferramentas e programas estruturados, mas do desenvolvimento de uma cultura voltada para a aprendizagem"[5]

Com a padronização de fabricação das peças e também de serviços, tem que seguir o passo-a-passo do processo de produção, com isto qualquer anomalia no produto ou serviço fica fácil de ser detectada e o problema possa ser resolvido o mais rápido possível. Caso o problema seja mais complexo que se pensava deverá ser feito um estudo de caso para se chegar a raiz do problema e assim sanar o problema para que no futuro não ocorra novamente.

Para se obter um bom trabalho e que a padronização das peças, bem como as normas e procedimentos sejam atendidos, tem que ter seu desenvolvimento lógico e direto, fazer as suas etapas de forma que atenda o que está especificado como falado por Juran (1988) o cliente não é somente o final, mas sim, o posto posterior e anterior, cada posto é seu cliente, bem como os departamentos, todos estão englobados no processo produtivo direto ou indiretamente. Para [6] "a melhoria da qualidade é muito diferente do 'combate a incêndios'. A melhoria contínua é um processo complementar às mudanças radicais consideradas pela reengenharia".

O princípio da melhoria contínua busca o aprimoramento constante dos processos organizacionais. A organização deve buscar continuamente a melhoria do seu desempenho global. O objetivo da melhoria contínua do SGQ é aumentar a capacidade da organização em atender de maneira eficaz seus clientes [7].

Processos e Operações: Em uma empresa industrial, entendemos como um processo o percurso realizado por um material desde que entra na empresa até que dela sai com um grau determinado de transformação. Por sua vez, uma operação é o trabalho desenvolvido sobre o material por homens ou máquinas em um determinado tempo [8].

O termo produtividade é hoje exaustivamente usado, não só nas publicações especializadas, como também no dia-a-dia da empresa. O termo produtividade, como vimos, foi utilizado pela primeira vez, de maneira formal, em um artigo do economista francês Quesnay em 1766. Decorrido mais de um século, em 1883, outro economista francês, Littre, usou o termo com o sentido de "capacidade para produzir". Entretanto, somente no começo do século XX, o termo assumiu o significado da relação entre o produzido (output) e os recursos empregados para produzi-lo (input).

Segundo [9], a história do surgimento da melhoria contínua data da Revolução Industrial quando Frederick Taylor e Frank Gilbreth advogaram o uso de método científico para chegar à melhor forma de produção (one best way). Os métodos científicos 
da administração exigem treinamento, sistematização, padronização, controle e determinação de uma metodologia para aumentar a eficiência e eficácia. Neste método há uma separação entre a mão de obra "pensante" e mão de obra "executora". Ainda segundo esses autores, esta separação entre "pensar" e "fazer" era considerado, por Henry Gantt, um aluno do Taylor, como uma desvantagem da administração científica que pode ser superada pela reintrodução dos trabalhadores nos processos de melhoria e para isso, é necessário deixar a cargo dos executantes das tarefas que sugerissem as melhores formas de realizar a atividade, pagando, assim, uma recompensa para as melhorias introduzidas por este.

A característica de fazer um trabalho que possa dá o resultado esperado para a melhoria do processo de fabricação de peças e equipamentos, tem que fazer análises em seu processo e adequar ao real procedimento adotado inicial e não se pode deixar que fique parado esta melhoria, mas sim dando continuidade para se chegar o mais próximo da excelência em produção. "Existem cinco abordagens principais para a definição de qualidade: transcendental, baseado no produto, baseado no usuário, baseado na produção e baseado no valor"[10].

A melhoria contínua em uma empresa é fundamentalmente a base para que o trabalho desenvolvido seja capaz de atender as expectativas esperadas para uma proposta de melhoria seja implantada e sua eficácia comprovada.

"O sistema de produção da Toyota é formada por apenas quatro regras implícitas que guiam a concepção, o projeto, operação e melhoria de qualquer atividade, relação ou fluxo para produto e serviço. Muitas pessoas, em suas visitas à Toyota, confundem o sistema com as técnicas e ferramentas que lá observam" [11].

$\mathrm{O}$ aprendizado é algo que deve acontecer nas organizações que estão motivadas a persistir no mercado competitivo e globalizado. Desta forma, as organizações são concebidas como sistemas vivos, que existem em um ambiente amplo do qual dependem em termos de satisfação das suas várias necessidades. Com essa metáfora, surge o desafio que designa oportunidades a uma série de atividades a serem inovadas, que contribui para a capacitação de auto-organização, onde se encontra o apoio da ferramenta melhoria contínua.

"A tecnologia de grupo é um conjunto de técnicas manufatureiras não nos permite explorar as similaridades básicas de peças e de processo manufatureiros a partir de sua classificação e codificação estruturada. Famílias podem ser classificadas por tamanho, forma, roteiros de fabricação ou por volume. A essência da técnica é o sistema de codificação. Cada parte recebe um código estruturado que descreve as características físicas da peça" [12].

As constantes mudanças têm como fundamento fazer com que o processo de fabricação seja o mais seguro para o atendimento da demanda, garantindo em sua totalidade que assegurará a qualidade dentro do menor tempo de entrega do produto. "As etapas dos processos devem ser desenhadas para poder ocorrer continuamente. Atividades em lotes devem ser eliminadas. Desta forma, é possível fornecer ao cliente o que ele deseja e somente quando ele deseja" [13].

\section{II.2 FERRAMENTAS DA QUALIDADE}

\section{II.2.1 BRAINSTORMING}

Brainstorming pode ser adaptado para o português como "tempestade de ideias" e é considerada uma das mais eficientes técnicas de geração de ideias em equipe. Foi aplicada inicialmente por Osborn em 1930.

Princípios do Brainstorming:

$\checkmark$ O Brainstorming baseia-se nos princípios da suspensão do julgamento e da geração do maior número possível de ideias.

\section{$\checkmark$ Preparação da sessão de Brainstorming}

$\checkmark$ Para que o sucesso seja obtido, a sessão de brainstorming deverá ser cuidadosamente planejada. Sucesso não combina bem com improviso.

\section{$\checkmark$ Condução da sessão de Brainstorming}

Após o início da sessão, os participantes podem apresentar as suas sugestões a qualquer momento, de forma bastante espontânea. À medida que as ideias são apresentadas, o secretário vai anotando-as em local bem visível, de forma que todos os participantes possam enxerga-las.

O coordenador deverá estar atento para não deixar que qualquer participante lance críticas às ideias apresentadas por outros participantes. Também deverá evitar, a todo custo, que o foco da sessão se desvie para outros assuntos.

\section{II.2.2 DIAGRAMA DE ISHIKAWA}

Em 1953, Ishikawa consolidou estudos realizados em uma fábrica na forma de um diagrama de causa-efeito. Essa representação gráfica permite estabelecer, após criteriosa, quais são as causas (problemas que dão início à ocorrência do problema maior) que fazem com que o efeito ocorra.

Diagrama de causa-efeito para identificação de causas partimos de um problema existente e tentamos, por meio da aplicação do diagrama, identificando as possíveis causas de seu aparecimento. Salientando que o processo deve ser muito bem conhecido para ser efetivo.

Como podemos perceber, o diagrama pode ser ajustado às necessidades da organização, primeiramente no estabelecimento das responsabilidades por meio da designação da autoridade de cada elemento ou ação. Percebemos também que a análise é representada pelos $6 \mathrm{Ms}$, que são:

$\checkmark \quad 1 \mathrm{M}$ (materiais): refere-se à análise das características de materiais quanto à sua uniformidade, padrão etc.;

$\checkmark 2 \mathrm{M}$ (máquina): diz respeito à operacionalidade do equipamento e ao seu funcionamento adequado;

$\checkmark 3 \mathrm{M}$ (método): considera a forma como serão desenvolvidas as ações;

$\checkmark$ 4M (meio ambiente): avalia qual situação pode ser a causa de um determinado efeito (situações de execução);

$\checkmark 5 \mathrm{M}$ (mão de obra): caracteriza o padrão da mão de obra utilizada, se ela é devidamente treinada, se tem as habilidades necessárias, enfim, se está qualificada para o desemprenho da tarefa;

$\checkmark$ 6M (medida): traduzida pela forma como os valores são representados (por distância, tempo, temperatura etc.) e pelos instrumentos de medição utilizados.

\section{II. $2.35 \mathrm{~W} 2 \mathrm{H}$}

A ferramenta $5 \mathrm{~W} 2 \mathrm{H}$ traduz a utilização de perguntas (elaboradas na língua inglesa) que se iniciam com as letras W e H, apontadas no qual também se encontra o significado de cada uma delas. As perguntas têm como objetivo gerar respostas que esclareçam o problema a ser resolvido ou que organizem as ideias na solução de problemas [14]. 
A utilização de tal ferramenta permite que um processo em execução seja dividido em etapas, estruturadas a partir das perguntas, com o intuito de serem encontradas as falhas que impedem o término adequado do processo. O resultado de sua aplicação não é a indicação clara das falhas, mas sim sua exposição para uma análise acurada.

\section{II.2.4 HISTOGRAMA}

Histograma são gráficos de barras que mostram a variação sobre uma faixa específica.

É uma ferramenta que nos possibilita conhecer as características de um processo ou um lote de produto permitindo uma visão geral da variação de um conjunto de dados.

São várias as aplicações dos histogramas, tais como:

$\checkmark$ Verificar o número de produto não-conforme; determinar a dispersão dos valores de medidas em peças; em processos que necessitam ações corretivas; para encontrar e mostrar através de gráfico o número de unidade por cada categoria.

\section{METODOLOGIA APLICADA}

Para melhor entendimento a orientação de [15] "a pesquisa de campo caracteriza-se pelas investigações em que, além da pesquisa bibliográfica e/ou documental, se realiza coleta de dados junto a pessoas, com o recurso de diferentes tipos de pesquisa (pesquisa ex-post-facto, pesquisa-ação, pesquisa participante, etc.)

A pesquisa dos problemas relacionados ao assunto que está sendo estabelecido fará com que haja um entendimento melhor dos fatos, conforme explica [16] "a grande maioria dessas pesquisas envolve: (a) levantamento bibliográfico; (b) entrevistas com pessoas que tiveram experiências práticas com o problema pesquisado; e (c) análise de exemplos que estimulem a compreensão".

Os questionamentos sobre o problema e qual direcionamento deve ser feito para resolver o problema, analisando todo o contexto do ambiente do relacionado ao fato que está levando ao problema. Esclarecem [17] "o modelo de análise constitui o prolongamento natural da problemática, articulando de forma operacional os referenciais e as pistas que serão finalmente escolhidos para guiar o trabalho de coleta de dados e a análise".

A pesquisa bibliográfica fará com que a solução do problema seja resolvido com mais rapidez, como explica [18] "a pesquisa bibliográfica, considerada mãe de toda pesquisa, fundamenta-se em fontes bibliográficas; ou seja, os dados são obtidos a partir de fontes escritas, portanto, de uma modalidade específica de documentos, que são obras escritas, impressas em editoras, comercializadas em livrarias e classificadas em bibliotecas" [18].

\section{RESULTADOS E DISCUSSÕES}

\section{IV.1 PROPOSTA DE SOLUÇÃO}

No processo de fabricação (compactação) da engrenagem, verificou-se que está após o processo, houve a necessidade de retirar o excesso de rebarba que está localizada na peça, tem manuseio em excesso, e posteriormente colocar novamente no processo, dando continuidade na sua fabricação. Para que não haja este processo "extra", será feito uma análise mais detalhada em seu processo de fabricação, utilizando as ferramentas da qualidade, a experiência de todos os envolvidos neste contexto do processo, assim agregará valores ao produto final.

O ajuste no processo, terá um impacto na sua produtividade, pois não será mais necessário fazer a retirada da rebarba e com isto também o manuseio da peça será menos e assim terá sua demanda produtiva normalizada, mas mesmo com todos os ajustes, não poderá deixar de fazer análise no processo para que garanta a sua eficiência, e caso seja necessário refazer as análises. "Ressaltam que para uma empresa que vai evoluir de uma conduta voltada a apagar incêndios, ou melhorias, é necessário estimular o processo de aprendizagem e gerenciar o conhecimento adquirido" [19].

O processo de compactação da engrenagem anteriormente era feito com matriz com vários postiços montados na parte superior e inferior, assim sendo, a proposta de eliminação da rebarba tem a melhoria de uma matriz na parte superior sem os postiços, ou seja, a parte superior é inteiriça (sem parte móvel), mas mesmo assim garantirá a qualidade da engrenagem e como a parte inferior tem peças móveis (com postiços) tem como, caso necessário, os ajustes no processo de compactação na engrenagem.

"Esta forma de organização do trabalho, orientada por grupos com objetivos e atividades em comum e formada por indivíduos com competências complementares, estimulam a formação de 'comunidades de prática'. Estas comunidades têm facilidade em desenvolver uma linguagem comum entre seus componentes, aumentando a capacidade de absorção de novos conhecimentos, favorecendo a aprendizagem num processo social e, consequentemente, a capacidade de desenvolver melhorias". [20].

Fazer a análise do processo de fabricação, verificando cada ponto que possa gerar a rebarba e com isto ter que fazer a retirada e perca de tempo e queda da qualidade.

Mapear este processo levará a causa raiz do problema da rebarba na peça, e desta forma, eliminar o processo de rebarbação e diminuir o manuseio da peça, que este também gerar perda do produto, e com isto tem um alto índice de rejeito na produção da engrenagem.

\section{IV.1 PROPOSTA DA MELHORIA DA MATRIZ DE COMPACTAÇÃO}

O planejamento segue um cronograma estabelecendo o processo de acompanhamento do desenvolvimento da proposta de eliminação da rebarbação da engrenagem. Tabela 1 com o cronograma.

O processo é mostrado na figura 1, descrevendo o passoa-passo da retirada da rebarba da engrenagem na linha de produção, que se inicia logo após a compactação da matéria-prima, assim formando a engrenagem [21]. 


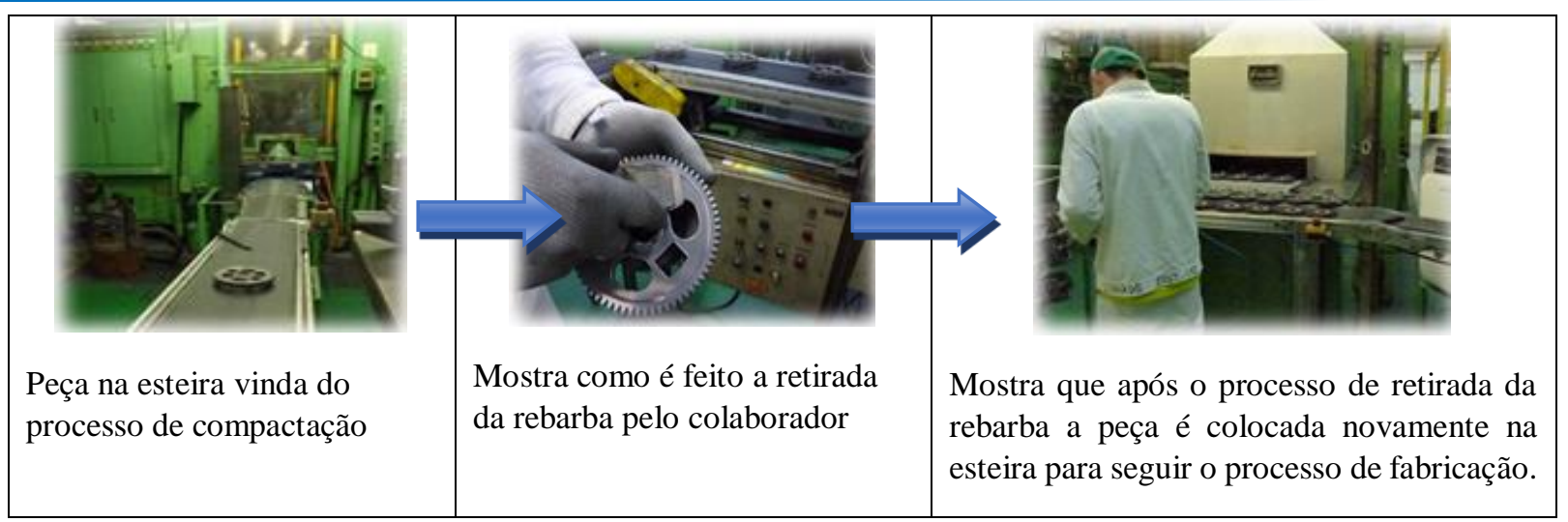

Figura 1: Passo-a-passo retirada da rebarba.

Análise dos parâmetros da rebarba da engrenagem (especificado e real).

Utilizando o histograma, fez com que a análise do problema seja identificado com notória alta de não conformidade da peça em relação aos demais produtos com a mesma especificação, desta forma terá que ser feito uma análise crítica mais profunda para que possa ser encontrado o real problema que causa este defeito e com isto tenha a necessidade de fazer a retirada do excesso de rebarba da engrenagem. No gráfico da Figura 2 mostra o Histograma, onde indica o parâmetro da rebarba conforme o especificado na figura 2 , sendo que é no máximo $0,15 \mathrm{~mm}$.

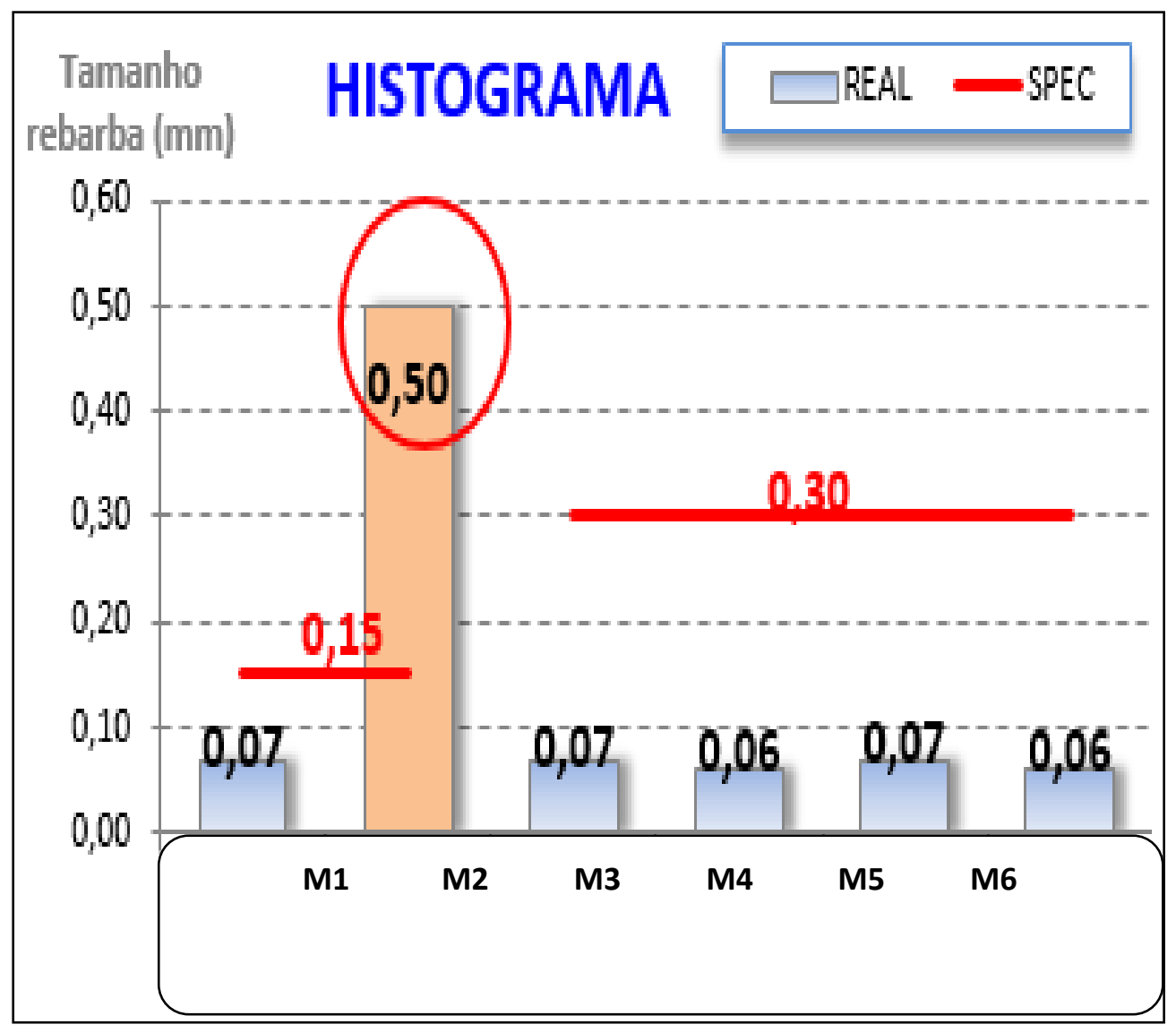

Figura 2: Gráfico de Histograma. 
Conforme o gráfico da Figura 2, mostra que a rebarba esta acima do especificado na figura 3 , tendo sido encontrado valor de $0,50 \mathrm{~mm}$, fazendo outras medições utilizando onde teve variação entre 0,40 a $0,50 \mathrm{~mm}$. Na figura 4 mostra onde esta o excesso de rebarba.

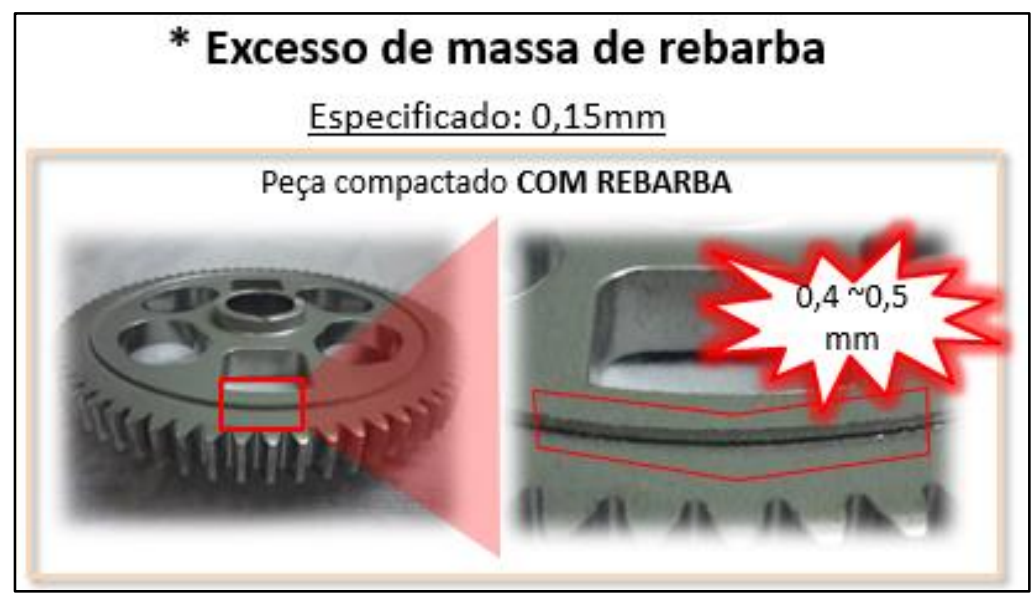

Figura 3: Local que está a rebarba.

Análise utilizando as Ferramentas Brainstorming, de retirar a rebarba seja ajustada e atenda as especificações do Diagrama de Ishikawa, 5W2H.

A necessidade de uma análise mais criteriosa, lança-se desenho técnico. Como mostrará na tabela 1 Brainstorming, será colocada as possíveis causas prováveis que resultará no problema mão de mais ferramentas para dá suporte neste procedimento para a melhoria no processo de compactação para a formação da da rebarba na engrenagem.

Tabela 1: Brainstorming.

\begin{tabular}{c|l}
\hline \multicolumn{2}{c}{ Análise da Causa da não conformidade - Método de Brainstorming } \\
\hline $\mathbf{1}$ & Falta de ajuste no ferramental \\
\hline $\mathbf{2}$ & Falta de manutenção no ferramental \\
\hline $\mathbf{3}$ & Controle de não conformidade, não atende o processo de fabricação \\
\hline $\mathbf{4}$ & Verificação dos materiais usados para a fabricação da peça \\
\hline
\end{tabular}

\section{IV.1.1 PROCESSO DE COMPACTAÇÃO}

No processo de compactação cada etapa foi mapeada de forma a verificar cada ponto do processo de fabricação e fazendo as análise passo-a-passo, analisando os pontos onde se dá o problema de rebarba com mais frequência e no mesmo local e/ou em partes diversas pelo perímetro da peça. Tabela 3 mostrará o passo-a-passo do processo de compactação, sendo a figura 4.

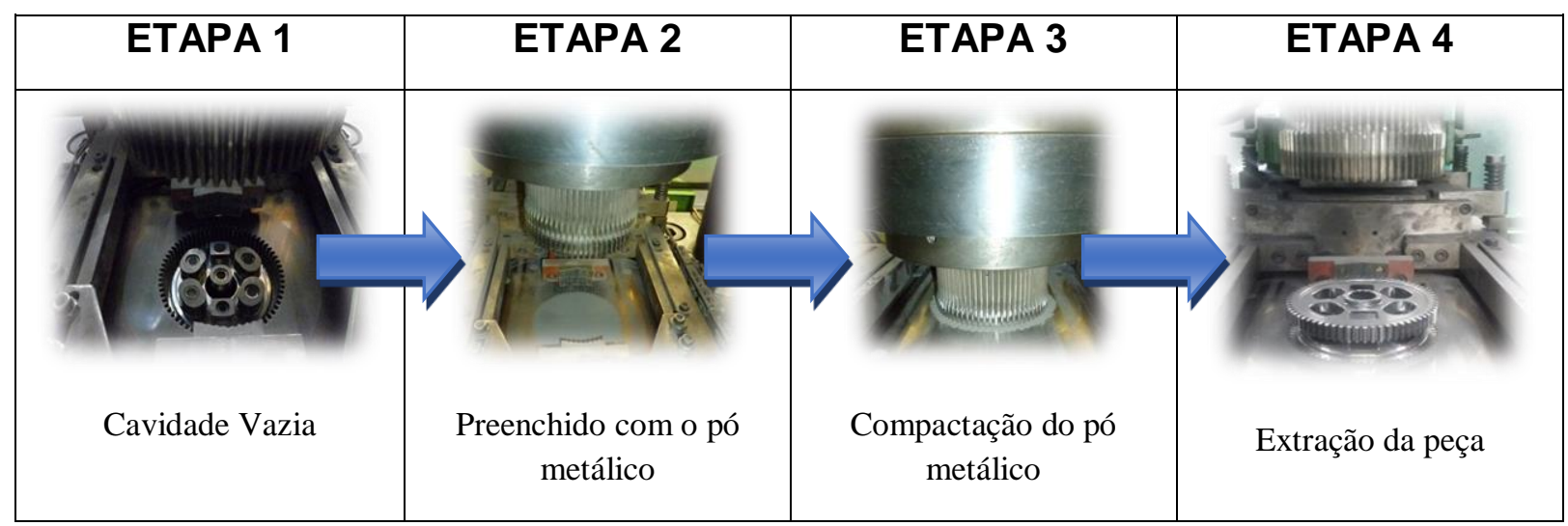

Figura 4: Sequência do processo de compactação da engrenagem. 
Durante a prensagem do material é o momento em que o mesmo ganha forma de um produto moldado conforme o formato/ perfil do molde, a rebarba se forma no momento da compactação (Etapa 3).

Esta análise mostra claramente que o problema da rebarba está na matriz de conformação, na figura 5 amostras os punções desmontados, devido a folga entre os punções figura 6 e com isto a rebarba encontra-se fora do especificado, salientando que no desenho contempla a não conformidade, porém com o limite máximo de $0,15 \mathrm{~mm}$.

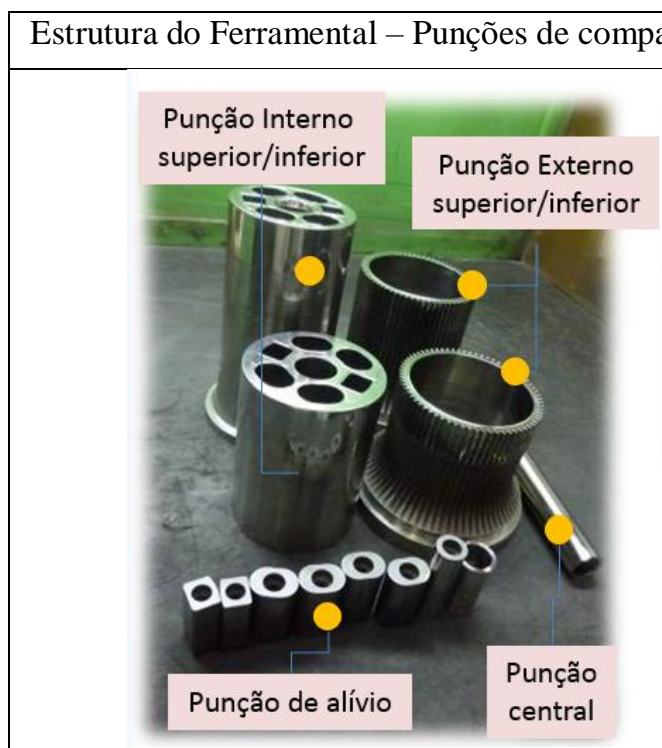

Figura 5 a

Punção de compactação da parte superior.

Os punções possuem movimentos independentes durante a compactação para assegurar o dimensional e taxa de compressão de cada área distintas.

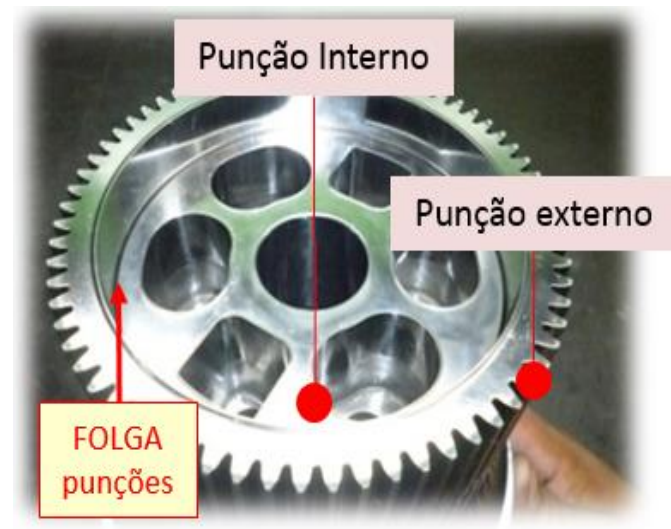

Figura $5 b$

Figura 5: Estrutura do Ferramental.

Nesta análise na Figura 7 no Diagrama de Ishikawa, verificou-se onde encontra-se os maiores problemas que geram a rebarba na engrenagem, com os dados gerados, poderá ser dado ao início de colocar a implantar a proposta

em prática, mas não pode parar por aqui, ainda tem alguns pontos que devem ser esclarecidos para a concretização da proposta.

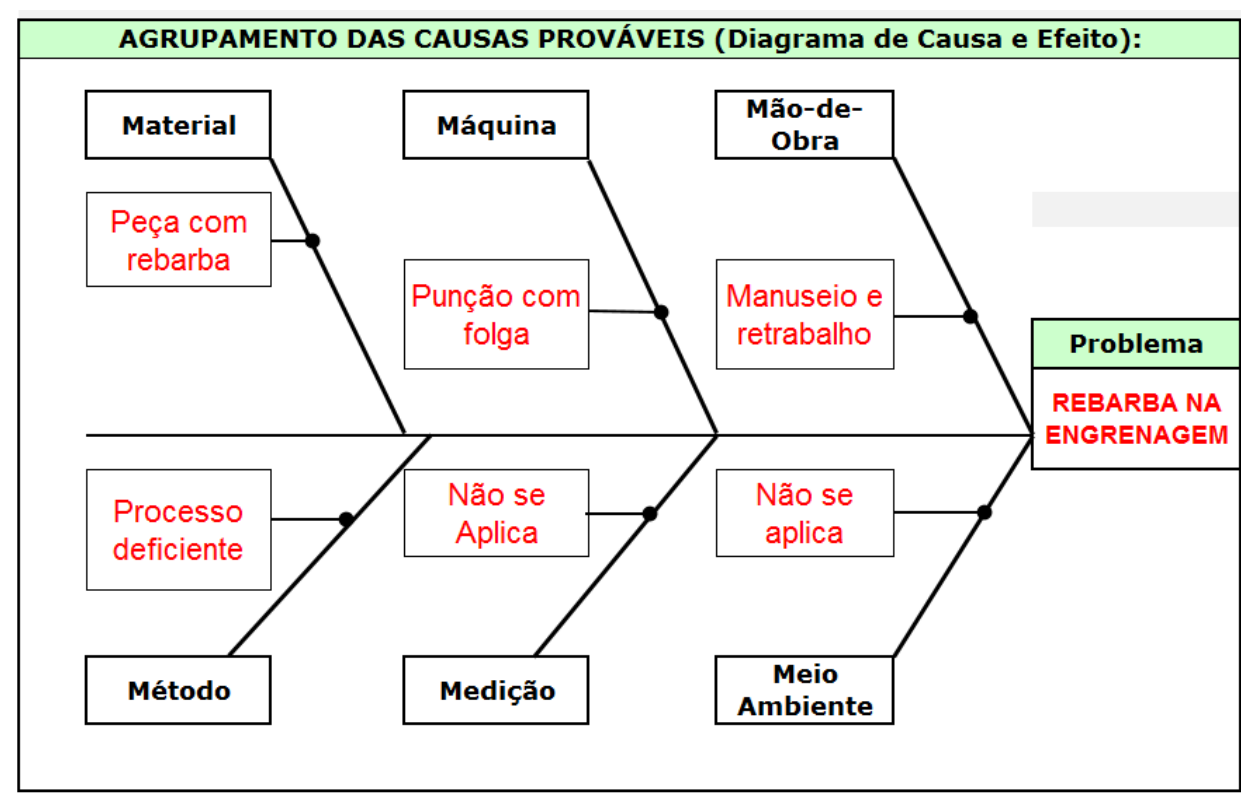

Figura 7: Diagrama de Ishikawa. 
A proposta de mudança será feita na matriz de conformação, ou seja, confeccionar uma nova, mas ao invés de ser em partes (postiços, punções e porta-punções separados) serão em uma única peça superior ou inferior. Contudo, esta proposta tem que se fazer de forma a garantir a qualidade do produto final.
Analisar ponto-a-ponto a mudança correlatada para que seja feito de forma a manter as características do produto, assim, a parte que for confeccionada inteira, a outra terá parte móveis, ou seja, independentes (postiços), pois desta forma garantirá que a possibilidade de ajustar para que se garanta a dureza, densidade e resistência como são apresentados os dados na Tabela 2.

Tabela 2: 5W2H.

\begin{tabular}{|c|c|c|c|c|c|c|}
\hline No. Da ação & $\begin{array}{c}\text { Ação a ser } \\
\text { implementada } \\
\text { (What - o Que) }\end{array}$ & $\begin{array}{l}\text { Requisitos aplicáveis } \\
\text { (Why - Por Quê) }\end{array}$ & $\begin{array}{c}\text { Procedimentos } \\
\text { envolvidos } \\
\text { (How-Como) }\end{array}$ & $\begin{array}{c}\text { Área } \\
\text { responsável } \\
\text { (Where-Onde) }\end{array}$ & $\begin{array}{l}\text { Responsável } \\
\text { (Who-Quem) }\end{array}$ & $\begin{array}{c}\text { Custo } \\
\text { (How Much) }\end{array}$ \\
\hline 1 & Punção com folga & $\begin{array}{l}\text { Devido ao excesso de } \\
\text { rebarba e manuseio }\end{array}$ & $\begin{array}{l}\text { Confecção do } \\
\text { punção superior }\end{array}$ & Ferramentaria & Ferramenteiro & $\mathrm{R} \$ 5.000,00$ \\
\hline 2 & Peça com rebarba & Excesso de rebarba & $\begin{array}{c}\text { Retirando a } \\
\text { rebarba }\end{array}$ & Produção & Operador & $\mathrm{R} \$ 34,00$ \\
\hline 3 & $\begin{array}{l}\text { Processo } \\
\text { deficiente }\end{array}$ & Não atende a demanda & $\begin{array}{l}\text { Ajustando o } \\
\text { ferrametnal }\end{array}$ & Ferramentaria & Ferramenteiro & $\mathrm{R} \$ 52,50$ \\
\hline \multirow[t]{2}{*}{4} & $\begin{array}{l}\text { Manuseio e } \\
\text { retrabalho }\end{array}$ & Excesso de manuseio & $\begin{array}{c}\text { Eliminando a } \\
\text { rebarba }\end{array}$ & Ferramentaria & Ferramenteiro & $\mathrm{R} \$ 3,45$ \\
\hline & & & & & TOTAL & $\mathrm{R} \$ \quad 5.089,95$ \\
\hline
\end{tabular}

Foi confeccionado punção da parte superior, que anteriormente era em duas partes, passou a ser um único punção. Desta forma a rebarba foi eliminado por não ter mais folga entre eles. As atividades geradas sanaram os problemas que foram apresentadas e a propostas implantada. A proposta também sanou o problema do manuseio em excesso da peça. O colaborador que fazia a retirada da rebarba, passou a executar o seu serviço que é de fazer a inspeção visual do produto.
A necessidade de fazer a mudança é a forma de diminuir ou até mesmo acabar com a rebarba, mesmo que seja inerente ao processo, mas que não está dentro do especificado, lançar mãos de todos os recursos que possam agregar valores a este processo de melhoria na compactação da engrenagem. Com uma parte dos dados em mãos, pois ainda terá que ser feito a análise final com a mudança feita e todas as inspeções referentes ao item dentro do desenho técnico. A mudança terá ainda mais alguns dados que devem contemplar valores a sua mudança e o que será também ganho com a implantação desta proposta.

\section{IV.1.2 VIABILIDADE ECONÔMICA}

Na tabela 3, mostrará o custo de cada item que será confeccionado referente a implantação proposta, com estes dados, podemos mostrar que será viável a implantação e desta forma a eliminação da rebarba.

Tabela 3: Viabilização Econômica.

\begin{tabular}{l|c|c}
\multicolumn{1}{c|}{ Ferramental } & Preço unitário atual (R\$) & Preço unitário Proposto (R\$) \\
\hline \multicolumn{1}{c|}{ Matriz } & 33.979 & 33.979 \\
\hline Punção Superior & - & $\mathbf{1 2 . 2 7 5}$ \\
\hline Punção Superior Externo & $\mathbf{9 . 7 7 4}$ & \\
\hline Punção Superior Interno & $\mathbf{9 . 0 6 3}$ & 9.774 \\
\hline Punção Inferior Externo & 9.774 & 7.669 \\
\hline Punção Inferior Interno & 7.669 & 2.840 \\
\hline Punção Ressalto Superior & 2.840 & 1.050 \\
\hline Punção Ressalto Inferior & 1.050 & 950 \\
\hline Pino Central & 950 & \\
\hline
\end{tabular}


Com os valores do custo de cada item referente a proposta de melhoria fará uma comparação mostrando o real custo com o problema e com a implantação da proposta o valor do ganho em relação ao processo de fabricação da engrenagem. Valores no mostrado no gráfico 2 .

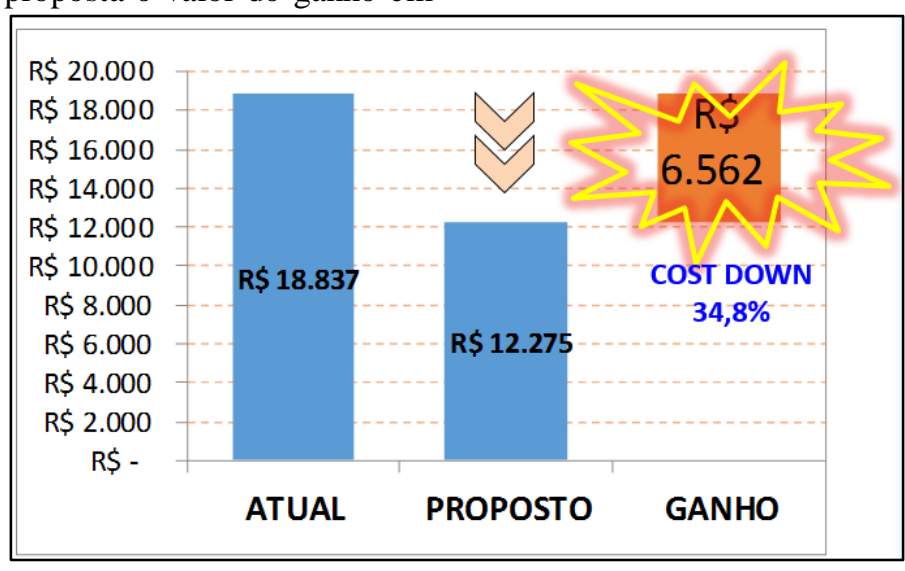

Figura 8: Gráfico do Custo.

Fonte: TECHNOCUT (São Paulo), (2016)

\section{IV.1.3 VIABILIDADE DA QUALIDADE DO PRODUTO}

O retrabalho de retirada da rebarba, traz consequências negativas na qualidade do produto por falha de material devido manuseio das peças VERDES (apenas compactado). A figuras $9 \mathrm{e}$ figura 10, mostra como é feito o processo após a compactação da engrenagem.

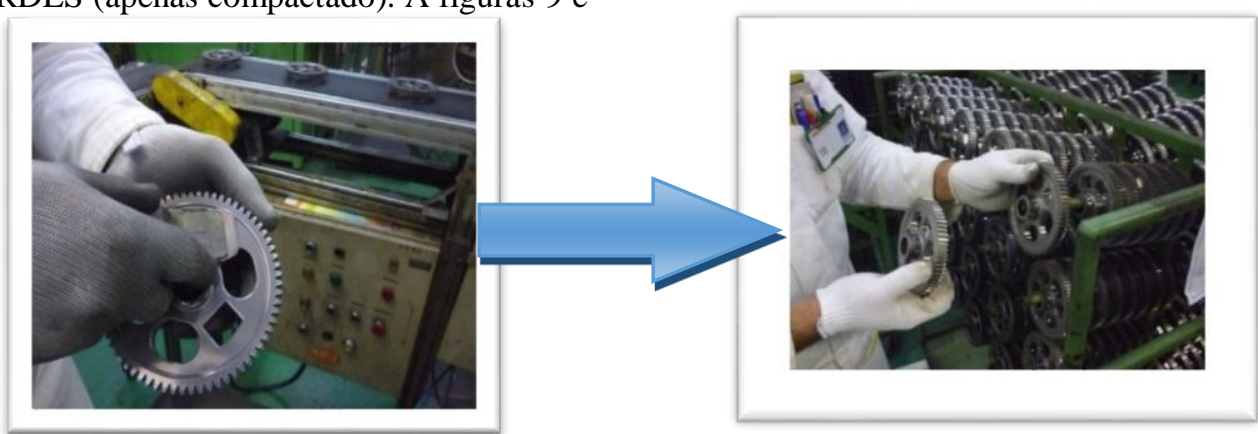

Figura 9: Processo de retirada da rebarba $100 \%$ manual.

Figura 10: Manuseio da peça.

No gráfico da Figura 11, mostrará o período de peças defeituosas, coletada base SGM: 01/julho/16 30/setembro/2016.

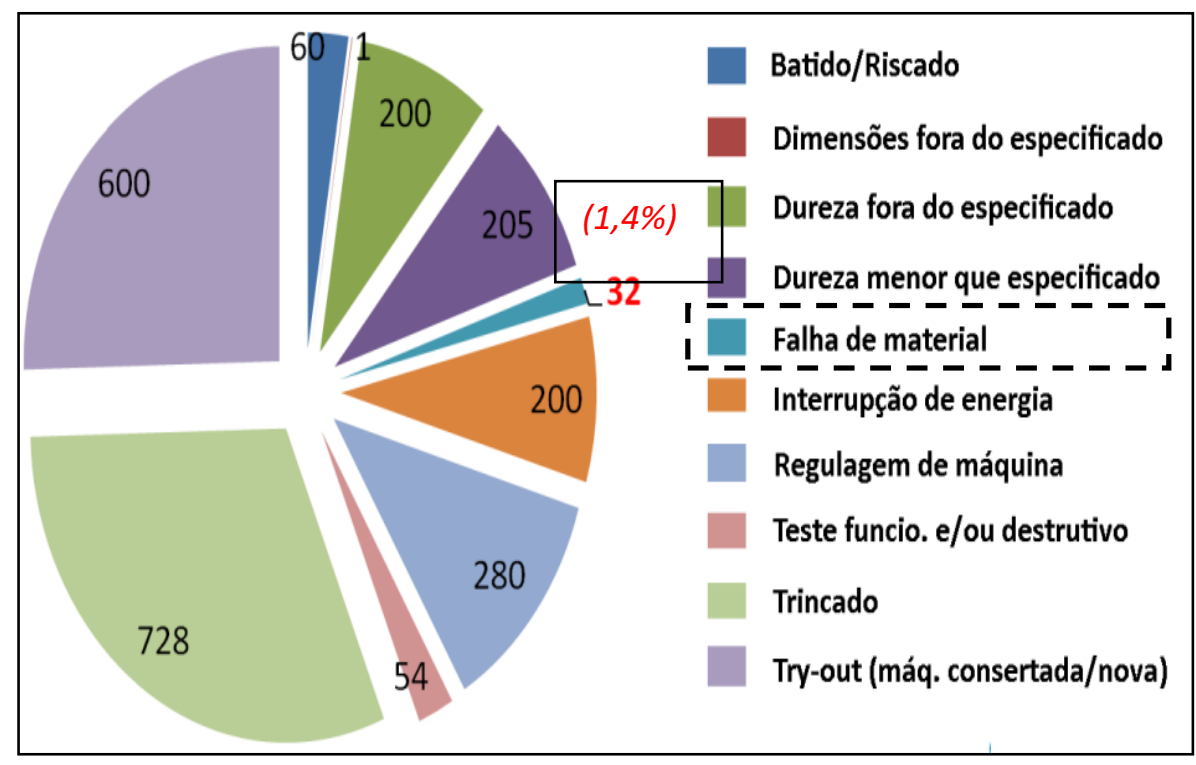

Figura 11: Coletas de dados. 
Desta forma com a eliminação da rebarba não teremos rejeições ocasionados por manuseio de peças pela retirada da rebarba.
A proposta transforma o meio de fabricação isenta de retrabalho devido a rebarba referente a compactação por ter folga entre os punções.

\section{IV.1.4 UNIFICAÇÃO DOS PUNÇÕES (INTERNO + EXTERNO).}

\section{IV.1.4.1 PROCESSO ATUAL}

Com o processo atual mostrado na Figura 12, os punções eram separados e montados no ferramental para que possa fazer a compactação do pó metálico, assim, o procedimento fabril apresenta algumas particularidades que podem fazer com que o problema da rebarba seja evidente ao seu término da compactação. A figura 12 mostram cada um separadamente.

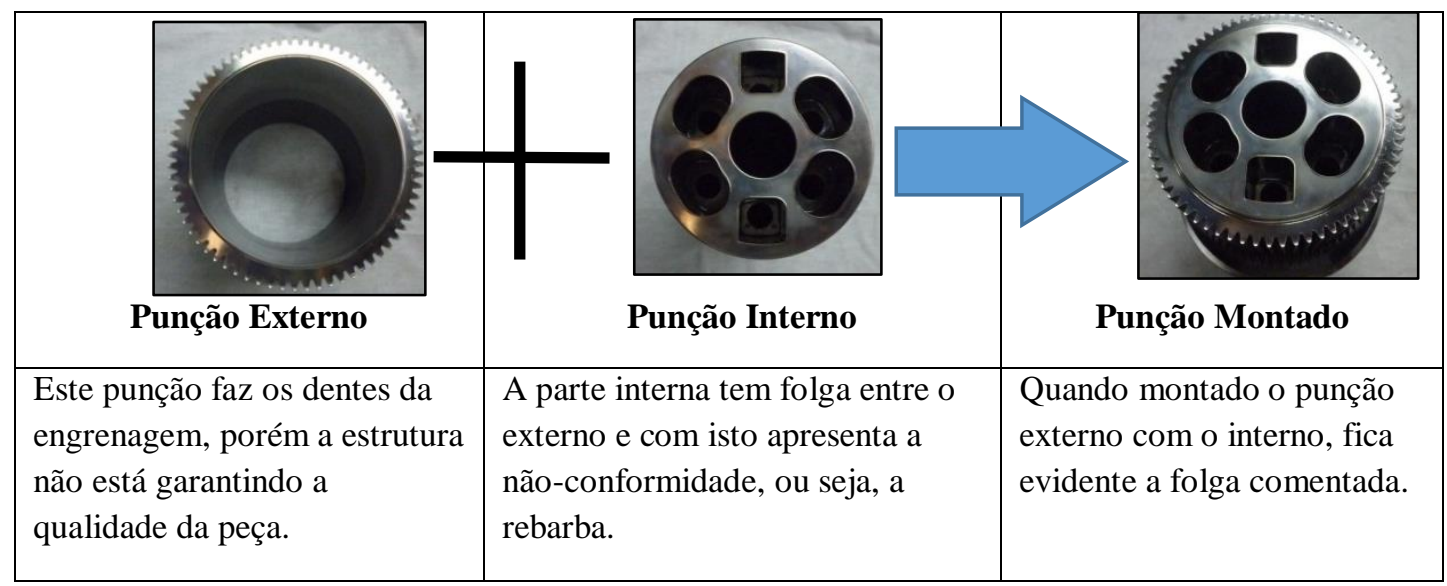

Figura 12: Punções separados.

\section{IV.1.4.2 PROPOSTA}

Confeccionar um (1) punção INTEIRO com as mesmas características (dimensão e precisão) ao invés de 2 punções.

Após concluirmos que este processo será a forma mais viável para a eliminação da rebarba, deu-se ao início de fazer o punção e os teste posteriores, coletando também os custos de cada material e o seu resultado final.
Parâmetros de qualidade para a rebarba conforme o desenho $0,15 \mathrm{~mm}$, meta estabelecida pela equipe $0,12 \mathrm{~mm}$. As análises feitas que estão, mostrada na figura 13, nos indica que a rebarba está fora do especificado, com isto a peça não fica plana. Na figura 13, mostra que a peça está plana, sem apresentar rebarba. Instrumento utilizado na medição foi o Contracer.

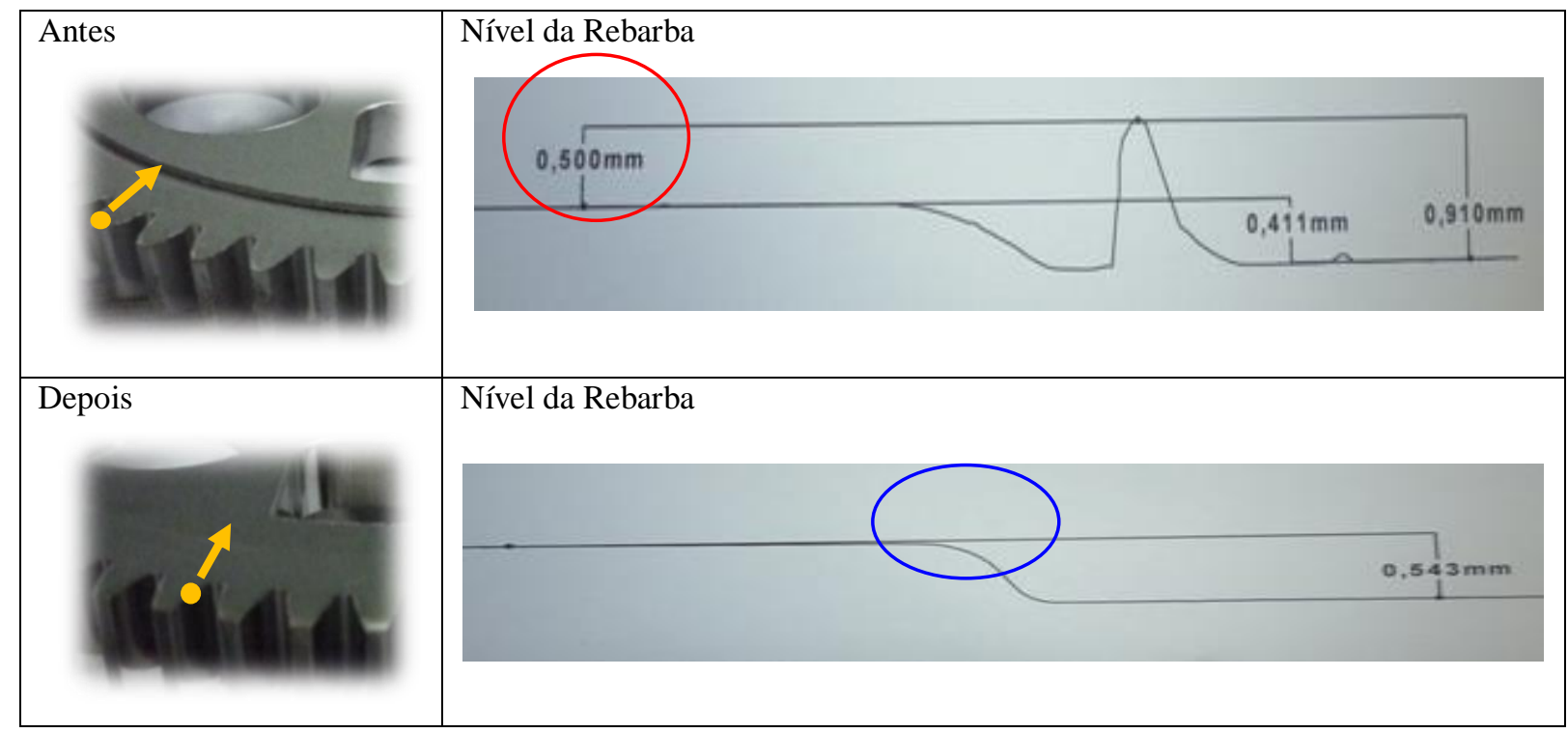

Figura 13: Ponto de inspeção verificando se há rebarba. 


\section{IV.1.5 CUSTO EM FERRAMENTAS}

A Tabela 4, mostrará o custo de cada punção do ferramental, também o custo do punção após a nova configuração, ou seja, sendo unificado os punções externo e interno da parte

Tabela 4: Custo do ferramental.

\begin{tabular}{|c|c|c|c|}
\hline Ferramental & $\begin{array}{c}\text { Preço } \\
\text { Unit. } \\
\text { Atual (R\$) }\end{array}$ & $\begin{array}{c}\text { Preço Unit. } \\
\text { Proposto (R\$) }\end{array}$ & $\begin{array}{l}\text { Qtd. } \\
\text { Anual }\end{array}$ \\
\hline Punção Superior & - & 12.275 & \multirow{3}{*}{2} \\
\hline $\begin{array}{l}\text { Punção Superior } \\
\text { Externo }\end{array}$ & 9. & - & \\
\hline $\begin{array}{l}\text { Punção Superior } \\
\text { Interno }\end{array}$ & $063 \quad 9$. & $\downarrow 34,8 \%$ & \\
\hline
\end{tabular}

superior do ferramental. No gráfico da Figura 14 a representação em escalas dos valores.

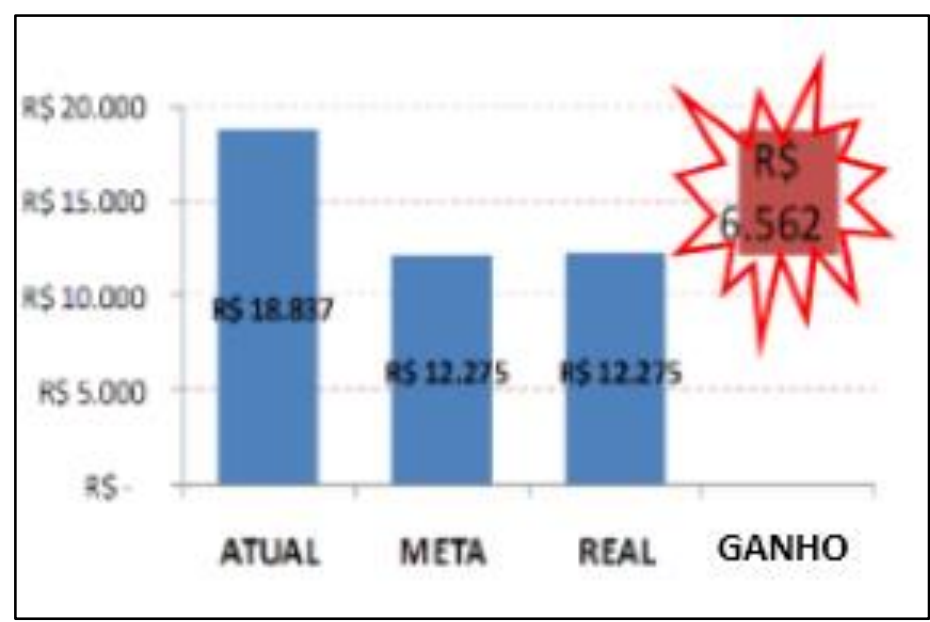

Figura 14: Gráfico da Escala de valores.

\section{IV.1.6 ANÁLISE DAS PEÇAS}

Análise da dureza da peça utilizando o Durômetro, com base na figura 14.

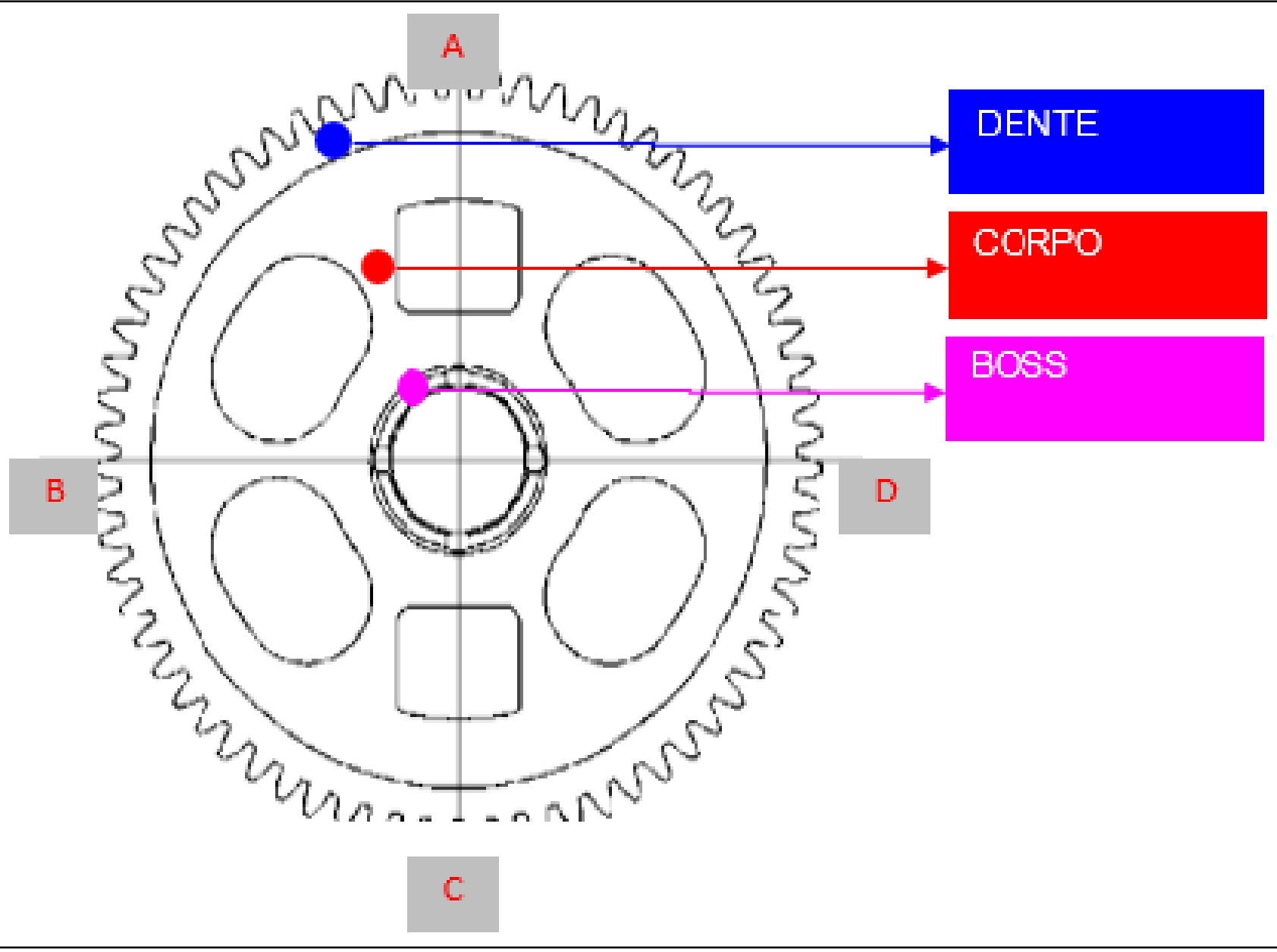

Figura 15: Desenho da engrenagem, pontos de inspeção de dureza. 
A Tabela 5 mostrará o resultado encontrado na análise da dureza nas engrenagens produzidas com o punção de compactação modificado.

Tabela 5: Resultado da dureza das peças com a modificação.

\section{DUREZA HRA - ESPECIFICADO 65 HRB}

\begin{tabular}{l|c|c|c|c|c|c}
\hline $\begin{array}{c}\text { Parte a ser } \\
\text { verificada }\end{array}$ & A & B & C & D & O & Aprovado \\
\cline { 5 - 7 } & & X & Reprovado \\
\hline Dureza Dente MC & 81 & 81 & 81 & 82 & $\mathbf{0}$ \\
\hline Dureza Dente OP & 83 & 82 & 83 & 83 & $\mathbf{0}$ \\
\hline Dureza Corpo MC & 79 & 80 & 79 & 80 & $\mathbf{0}$ \\
\hline Dureza Corpo OP & 81 & 81 & 82 & 80 & $\mathbf{0}$ \\
\hline Dureza Boss MC & 79 & 79 & 79 & 78 & $\mathbf{0}$ \\
\hline Dureza Boss OP & 77 & 75 & 76 & 76 & $\mathbf{0}$ \\
\hline
\end{tabular}

Na avaliação dos dados, chega-se à conclusão de que a proposta de unificação dos punções na parte superior está aprovada parcialmente, para que possa entrar no processo de produção da peça e com isto a eliminação da rebarba foi feita com sucesso esperado. O seu procedimento de aprovação, para efetivação da implementação da proposta, será feito conforme a liberação do lote piloto para teste, tenha um lote maior a serem analisadas, e os dados comparados com as das peças produzidas no ferramental modificado.

\section{PLANEJAMENTO DA PROPOSTA}

Com a característica de ajustar o procedimento de fabricação da engrenagem faz-se necessário um embasamento de pensamentos e técnicas para que haja o desenvolvimento da adequação para a implantação da proposta de melhoria, com isto, a forma correta de fazer com que tenha o objetivo alcançado para determinar a solução do problema da rebarba que a engrenagem possui após a sua compactação. Para Ohno ressalta que "o trabalho em equipe é tudo", isto significa que quando o trabalho é realizado em equipe, a soma de todos os esforços certamente atingirá a meta almejada com maior eficácia" [22].

$\mathrm{Na}$ Tabela 6, esta descritos todas as atividades relacionadas ao processo de análise e implantação da proposta de melhoria no processo de manufatura da engrenagem da motocicleta.

Tabela 10: Cronograma do Planejamento da Proposta.

\begin{tabular}{|c|c|c|c|c|c|c|c|c|c|c|c|c|c|c|c|c|c|}
\hline \multicolumn{18}{|c|}{ TABELA DO CRONOGRAMA DO PLANEJAMENTO DA PROPOSTA } \\
\hline \multirow{2}{*}{ Itens } & \multirow{2}{*}{ Atividades } & Jul & \multicolumn{3}{|c|}{ Ago } & \multicolumn{3}{|c|}{ Set } & \multicolumn{3}{|c|}{ Out } & \multicolumn{3}{|c|}{ Nov } & \multicolumn{3}{|c|}{ Dez } \\
\hline & & \begin{tabular}{l|l|l|l}
1 & 15 & 30 \\
\end{tabular} & & 15 & & 1 & & 30 & 1 & & 30 & 1 & & 30 & 1 & & 30 \\
\hline 1 & Análise do problema & & & & & & & & & & & & & & & & \\
\hline 2 & Proposta para eliminar o problema & & & & & & & & & & & & & & & & \\
\hline 3 & Avaliação da engenharia à proposta & & & & & & & & & & & & & & & & \\
\hline 4 & Fazer a implantação da proposta & & & & & & & & & & & & & & & & \\
\hline
\end{tabular}

\section{CONCLUSÃO}

Este trabalho tem a finalidade de solucionar o problema com base nos estudos, artigo e métodos para que tenha o resultado satisfatório na conclusão do problema. A forma de observar, analisando todos os pontos que podem ter causado ou causar o problema em questão, fará com que o pensamento crítico dos fatos relacionados sejam visto com clareza e objetividade. Todos os envolvidos devem ter consciência de que todos têm algo a dá com sua experiência.
Todas as possibilidades de chegar ao resultado esperado para eliminar a rebarba na engrenagem da motocicleta. As ideias foram fluindo de forma a se obter várias formas de solucionar o problema. As atividades descritas foram cumpridas por todos os envolvidos e todos os dados foram arquivados para que posteriormente seja feito novas análises do processo, para que se houver qualquer problema, tenha dados iniciais ganhando tempo nas análises, verificando os pontos que foram levantados e que podem ajustar o processo já existente. A melhoria contínua no processo, faz com que as ideias possam ser aplicadas com objetividade atingindo o patamar de qualidade e produtividade. 
Solucionando o problema descrevendo o seu escopo agregando os dados e coordenando as ações que podem fazer com que este problema não tenha reincidência futura e que o passo dado seja o início para um novo processo na melhoria contínua.

Os fatos relevantes que foram abordados no que se diz respeito a rebarba na peça, mostrando que a falha, o desgaste, e a falta de manutenção do ferramental são os fatores impactantes no aparecimento do problema. $\mathrm{O}$ andamento da análise, observando todo o passo-a-passo do processo fez com que os dados levantados possam dá o suporte para a solução do caso estudado e o procedimento que será adotado seja um patamar para solucionar outros problemas de qualidade e produtividade.

Concluindo no final que a necessidade de fazer melhorias devem ser agregadas ao seu dia-a-dia, sempre tendo a visão do todo o processo produtivo, observando suas peculiaridades e relevância a sua fabricação, garantindo a qualidade e satisfação do cliente interno e externo. Com isto, tudo que dá para fazer, tem uma solução para o seu problema.

\section{REFERÊNCIAS}

[1] JUNIOR, I. M.; ROCHA, A. V.; MOTA, E. B.; QUINTELLA, O. M. Gestão da Qualidade e Processos. Rio de Janeiro, Ed. FGV,

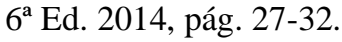

[2] http://marketingfuturo.com/wp-content/uploads/2012/09/Oque-e-Histograma-Quando-usar-e-Como-fazer-um-histograma.jpg

[3] LUCINDA, M. A. Ferramenta para a geração de ideias BRAINSTORMING - Qualidade: Fundamentos e Práticas para Cursos de Graduação - Marcos Antônio Lucinda - Rio de Janeiro, Editora BRASPORT, 2010. Ed. 1. Páginas 13-63-67-69.

[4] JAGER, B.; MINNIE, C.; JAGER, J.; WELGEMOED, M.; BESSANT, J.; FRANCIS, D. Enabling continuous improvement: a case study of implementation. Journal of Manufacturing technology Management, v. 15, n. 4, p. 315-324, 2004. http://dx.doi. org/10.1108/17410380410535017.

[5] GONZALEZ, R. V. D.; MARTINS, M. F. Melhoria contínua no ambiente ISO 9001:2000: estudo de caso em duas empresas do setor automobilístico. Revista Produção, v. 17, n. 3, p. 592603, 2007.

[6] TERZIOVSKI, M. Achieving performance excellence through an integrated strategy of radical and continuous improvement. Measuring Business Excellence, v. 6, n. 2, p. 5-14, 2002. http://dx.doi. org/10.1108/13683040210431419.

[7] TERRA, J. C. C. Gestão do conhecimento e E-learning na prática. Rio de Janeiro: Elsevier, 2003.

[8] DRUCKER, P. F. Aprendizado organizacional: Gestão de pessoal para inovação. Rio de Janeiro: Campus, 2000.

[9] SCHROEDER, D. M., \& ROBINSON, A. G. (1991). America Most Successful Export to Japan - Continuous Improvement Programs. Sloan Management Review, 32(3), 67-81.

[10] GARVIN, D. A. Gerenciando a Qualidade: a visão estratégica e competitiva. Tradução de João Ferreira Bezerra de Souza. Rio de Janeiro: Qualitymark, 2002.

[11] SPEAR, S.; BOWEN, H. K. Decoding the DNA of the Toyota production system. Harvard Business Review, p, 96-106,
Sep.-Oct, 1999. Petrônio G. Martins e Fernando Piero Laugeni, Administração da Produção - 2a ed. pág. 461.

[12] GAITHER, N. Production and operations management. $5^{\text {th }}$ ed. Orlando, FL: Harcourt Brace Jovanovitch Publishers, 1992, p. 133. - Petrônio G. Martins e Fernando Piero Laugeni, Administração da Produção - $2^{\mathrm{a}}$ ed. pág. 484.

[13] WOMACK, J. P.; JONES, D. T. Beyond Toyota: how to root out waste and pursue perfection. Harvard Business Review, reprint 96511, p. 1-16, Set-Oct, 1996. Petrônio G. Martins e Fernando Piero Laugeni, Administração da Produção - 2a ed. pág. 463.

[14] SELEME, R.; STADLER, H. Ferramenta 5W2H - Controle da Qualidade - As Ferramentas Essenciais, Abordagem Gerencial. Curitiba, Editora IBPEX, $2^{\text {a }}$ Ed. rev. e atual. 2010, pág. 42-91-93-100-101.

[15] FONSECA, J. J. S. Metodologia da pesquisa científica Fortaleza: UEC, 2002. Apostila.

[16] GIL, A. C. Como elaborar projetos de pesquisa. 4. ed. São Paulo: Atlas, 2007.

[17] QUIVY, R.; CAMPENHOUDT, L. V. Manuel de recherche en sciences sociales. Paris: Dunod, 1995, p. 149.

[18] DOXSEY J. R.; DE RIZ, J. Metodologia da pesquisa científica. ESAB - Escola Superior Aberta do Brasil, 2003, p. 45.

[19] BECKETT, A. J.; WAINWRIGHT, C. E. R.; BANCE, D. Implementing an industrial continuous improvement system: a knowledge management case study. Industrial Management \& Data Systems, v. 100, n. 7, p. 330-338, 2000 http://dx.doi.org/10.1108/02635570010349113.

[20] BROWN, J. S.; DUGUID, P. Knowledge and Organization: A social-practice perspective. Organization Science, v. 12, n. 2, p. 198-213, 2001. http://dx.doi.org/10.1287/ orsc.12.2.198.10116.

[21] http://www.ebah.com.br/content/ABAAAfTk0AJ/trabalhosobre-engrenagens.

[22] OHNO, T. O Sistema Toyota de Produção. Porto Alegre: 